\title{
Faixa de domínio e sua relação com a redução de vibrações produzidas por trens de superfície em áreas urbanas
}

\author{
Gianna Vanessa de Assis Chaves ${ }^{1}$; Roberto Leal Pimentel'; \\ Ricardo Almeida de Melo ${ }^{3}$; Jackson Pedrosa de Farias ${ }^{4}$
}

\begin{abstract}
Resumo: A utilização de uma faixa de domínio de trinta metros ao longo de ferrovias brasileiras foi motivada pela necessidade de segurança e evitar que a Administração Pública, se necessitar incorporar área ao patrimônio público em futura ampliação da ferrovia, tenha de desapropriá-la com maiores custos. Neste estudo, buscou-se investigar a influência da faixa de domínio de ferrovias na redução dos efeitos da vibração produzida pelo tráfego de trens em áreas urbanas. Através de monitoramento experimental da vibração induzida pelo tráfego de trens de passageiros, concluiu-se que a atual dimensão da faixa de domínio de ferrovias (30 metros), adotada pelas operadoras de ferrovias nacionais, é eficiente na redução da vibração devido ao amortecimento geométrico da vibração. Todavia, resultados de simulações evidenciaram que esta faixa não seria suficiente para redução dos níveis de vibração produzidos pelo tráfego de trens de carga, de modo a atender limites propostos por normas internacionais.
\end{abstract}

\begin{abstract}
The use of a railroad right of way along the Brazilian's railway lines was motivated by the need for security and to avoid that the Government, if in need of incorporating areas for future expansion of railway, would face high costs. In this paper, the influence of this railroad right of way in reducing the effects of vibration generated by the traffic of trains in urban areas was investigated. By measuring vibration induced by the traffic of passenger trains, it was concluded that the current width of the right of way (30 meters), adopted by railway operators in national railroads is effective to reduce the level of vibration due to a geometric damping effect. However, results from simulations of the vibration induced by the traffic of freight trains indicated a possibility that this width would not meet the needs of low level of vibration required by international standards.
\end{abstract}

\section{INTRODUÇÃO}

O aumento populacional, o avanço tecnológico e as práticas comerciais e industriais têm provocado muitos prejuízos para o meio ambiente, das mais diversas naturezas. A ocorrência de problemas de vibração é um exemplo de fator da degradação da qualidade ambiental urbana. Os centros urbanos estão sujeitos a crescentes problemas com o aumento da vibração produzida por tráfego. A implantação de grandes vias de transporte, como trens de superfície e metrôs subterrâneos (passageiros ou carga), são fontes de vibração em meio urbano.

Os trens de superfície, especificamente, representam fonte potencial de vibração, onde cargas móveis de expressiva intensidade atuam em conjunto com irregularidades das vias na produção de forças dinâmicas, tendo como resultado uma geração de ondas que são

\footnotetext{
${ }^{1}$ Gianna Vanessa de Assis Chaves, Universidade Federal da Paraíba, Programa de Pós-Graduação em Engenharia Urbana e Ambiental, João Pessoa, PB, Brasil. (e-mail: gianna_vanessa@hotmail.com).

${ }^{2}$ Roberto Leal Pimentel, Universidade Federal da Paraíba, Programa de Pós-Graduação em Engenharia Urbana e Ambiental João Pessoa, PB, Brasil. (e-mail: r.pimentel@uol.com.br).

${ }^{3}$ Ricardo Almeida de Melo, Universidade Federal da Paraíba, Programa de Pós-Graduação em Engenharia Urbana e Ambiental, João Pessoa, PB, Brasil. (e-mail: ricardo@ct.ufpb.br).

${ }^{4}$ Jackson Pedrosa de Farias, Universidade Federal da Paraíba, Programa de Pós-Graduação em Engenharia Urbana e Ambiental João Pessoa, PB, Brasil. (e-mail: mayllonjp@hotmail.com).
}

Manuscrito recebido em 14/7/2008 e aprovado para publicação em 15/6/2009. Este artigo é parte de TRANSPORTES, volume XVII, número 1, junho de 2009. ISSN: 1415-7713. transmitidas das vias de circulação, através dos solos adjacentes, até as fundações das edificações. Estas movimentações do solo das fundações podem ocasionar o agravo de patologias já existentes ou gerar danos (fissuras, trincas, etc.) nas edificações, de ordem funcional ou estrutural.

No Brasil, a utilização de uma faixa "non aedificandi" de trinta metros ao longo de ferrovias (faixa de domínio) foi motivada pela necessidade de segurança e, também, de evitar que a Administração Pública, se necessitar incorporar a área ao patrimônio público para ampliação futura da ferrovia, tenha de desapropriála com maiores custos e dificuldade de investimento na posse.

Contudo, diante da real possibilidade de danos às edificações e de prejuízos às populações das áreas lindeiras às vias férreas, devido à vibração induzida pelo tráfego de trens, surgem duas questões a serem consideradas:

- A atual dimensão de faixa de domínio de ferrovias, adotada no Brasil, garante suficiente redução da intensidade de vibração produzida por trens de superfície, de modo a não ocasionar problemas de integridade nas edificações lindeiras?

- Qual seria a faixa de domínio mínima (atrelada ao problema da vibração) a ser adotada em áreas urbanas por um sistema de transporte sobre trilhos de superfície, e qual o fundamento técnico para o(s) valor(es) especificado(s)?

Foi então realizado um diagnóstico das condições 
da ocupação urbana e dos efeitos da vibração produzida pela passagem de trens de superfície em edificações, no entorno de uma via férrea típica ao cenário nacional. Mediante medições, as características de atenuação de vibrações induzidas com relação à distância da ferrovia foram avaliadas.

\section{CARACTERIZAÇÃO E AVALIAÇÃO DA VIBRAÇÃO PRODUZIDA POR TRENS}

Um problema de vibração, em geral, possui três elementos, isto é, a fonte, o trajeto e o receptor. Compreender como cada um destes três elementos influencia na vibração é crucial no prognóstico e na mitigação do problema de vibração produzida pelo tráfego em meio urbano.

\subsection{A fonte}

Especificamente, para o estudo da vibração produzida por trens, a fonte da vibração é o conjugado tremtrilho. Segundo Rives et al. (1977 apud Semprebone, 2006), o trilho, fundamento da via, é o elemento ativo da estrutura ferroviária e está submetido a diversas ações dinâmicas. A movimentação dos veículos gera o desenvolvimento de ações dinâmicas verticais, que são propagadas pelo solo em formas de ondas. Ou seja, a fonte da vibração é função da variação da carga do veículo ferroviário com o tempo. A intensidade dessas vibrações também depende da qualidade das superfícies de rolamento.

Os fatores que podem influenciar na magnitude da vibração produzida pelo conjugado trem-trilho são: o tipo de veículo, massa total e a velocidade de tráfego (Bahrekazemi, 2004; Kim e Lee, 2000; Auersch, 2006).

\subsection{O trajeto}

As ondas de vibração podem chegar até as edificações por propagação através do solo, sendo este processo influenciado pelas propriedades deste último. Athanasopoulos et al. (2000) descreve que a amplitude das ondas de vibração propagadas em solo é atenuada à medida que a distância em relação à fonte da vibração aumenta. De acordo com estes autores, uma porção desta atenuação é causada pela distribuição da energia de vibração sobre a crescente área da superfície da frente de onda. Este tipo de atenuação é conhecido como amortecimento geométrico ou amortecimento externo. Enquanto o amortecimento geométrico ocorre devido à diminuição da densidade energética com a distância da fonte, outro tipo de amortecimento, o amortecimento interno ou amortecimento do material, acontece através da dissipação de energia pelo movimento das partículas. O amortecimento do material é função de vários parâmetros, incluindo: tipo de solo, umidade, composição mineralógica e temperatura.

\subsection{O Receptor}

A vibração induzida pode ser transmitida às estruturas de edificações e, principalmente, a painéis, como lajes e paredes de alvenaria e, também, a componentes secundários, como revestimento, vidros das janelas e outros. O problema da vibração em edificações é que havendo coincidência ou proximidade entre as freqüências da excitação com as freqüências de vibração dos componentes construtivos e/ou da própria estrutura, poderá ocorrer amplificação.

\subsubsection{Métodos de avaliação da vibração em edificações}

Na maior parte das recomendações a respeito do controle da vibração em edificações, considera-se na avaliação de danos estruturais, a freqüência da vibração (Bacci et al., 2003). Em conjunto com isto, são freqüentemente utilizados critérios de danos expressos em faixas de amplitudes de respostas (estimadas ou medidas), em termos da velocidade de pico de partícula ("Peak Particle Velocity - PPV"), usualmente em $\mathrm{mm} / \mathrm{s}$ e medidas em três direções (vertical, longitudinal e transversal, em relação à posição da fonte).

\subsubsection{Principais normas recomendadas para o controle da vibração em edificações}

No Brasil, a NBR 9653 (1986) estabelece como limite para controle de vibração, produzida por explosivos em edificações, o valor limite de $15 \mathrm{~mm} / \mathrm{s}$ de $\mathrm{PPV}_{\text {máxima, }}$ para a resultante das três direções (vertical, longitudinal e transversal). Nesta norma não se consideram faixas de freqüência de excitação associadas aos limites de PPV, o que pode ser uma limitação, já que, como citado anteriormente, determinadas faixas de freqüências são danosas às estruturas, podendo causar o fenômeno da ressonância.

Cabe observar que a NBR 9653 não estabelece correlações entre as diferentes características dos elementos envolvidos, que é o caminho seguido pela maior parte das normas internacionais ligadas ao problema da vibração em edificações, a exemplo da DIN 4150-3 (1999) e ISO 4866 (1990). Fatores relativos ao receptor (edificação), como o tipo e a condição (estado de conservação e/ou degradação), idade, tipo de fundação, tipo de solo local e importância social (se hospital, escola, prisão etc.), são considerados na avaliação dos eventuais possíveis danos causados pela vibração.

Outros países europeus desenvolveram suas próprias normas, baseando-as na ISO 4866 (1990) ou relacionando-as a ela, a exemplo da norma inglesa BS 7385 (1990). Contudo, esta última norma não delimita quais níveis são passíveis de provocarem danos.

As avaliações com a DIN 4150-3 (1999) baseiam-se no máximo valor absoluto da velocidade dos sinais medidos, em mm/s, para as três componentes da velocidade (vertical, longitudinal e transversal) (Tabela 1). 
Tabela 1. Valores de velocidade de partícula admitidos pela DIN 4150-3, utilizados na avaliação dos efeitos da vibração de curta duração em estruturas. Fonte: DIN 4150-3 (1999)

\begin{tabular}{c|c|c|c|c}
\hline \multirow{2}{*}{ Tipos de Estrutura } & \multicolumn{3}{|c|}{ Vibração na Fundação } & \multirow{2}{*}{$\begin{array}{c}\text { Vibração em plano } \\
\text { horizontal em } \\
\text { pavimentos superiores }\end{array}$} \\
\cline { 2 - 5 } & \multicolumn{3}{|c|}{ Freqüencia (Hz) } & Qualquer freqüência \\
\cline { 2 - 5 } & $\mathbf{1 ~ H z ~ a ~ 1 0 ~ H z}$ & $\mathbf{1 0 ~ H z ~ a ~} \mathbf{5 0 ~ H z} \mathbf{~ H z ~ a ~ 1 0 0 ~ H z}$ & $40 \mathrm{~mm} / \mathrm{s}$ \\
\hline Edifícios industriais & $20 \mathrm{~mm} / \mathrm{s}$ & 20 a $40 \mathrm{~mm} / \mathrm{s}$ & 40 a $50 \mathrm{~mm} / \mathrm{s}$ & $15 \mathrm{~mm} / \mathrm{s}$ \\
\hline Habitações & $5 \mathrm{~mm} / \mathrm{s}$ & 5 a $15 \mathrm{~mm} / \mathrm{s}$ & 15 a $20 \mathrm{~mm} / \mathrm{s}$ & $8 \mathrm{~mm} / \mathrm{s}$ \\
\hline Edifícios delicados & $3 \mathrm{~mm} / \mathrm{s}$ & 3 a $8 \mathrm{~mm} / \mathrm{s}$ & 8 a $10 \mathrm{~mm} / \mathrm{s}$ & \\
\hline
\end{tabular}

Para vibrações de curta duração, a DIN 4150-3 (1999) estabelece limites para o máximo valor (de pico) de qualquer das três componentes da velocidade, entre 3 e $50 \mathrm{~mm} / \mathrm{s}$, conforme a tipologia dos edifícios e as freqüências predominantes. As freqüências são consideradas em três intervalos: valores menores que 10 $\mathrm{Hz}$, valores entre 10 e $50 \mathrm{~Hz}$ e valores entre 50 e 100 Hz. A DIN 4150-3 (1999) prevê que, para freqüências acima de $100 \mathrm{~Hz}$, os valores indicados na coluna de 50 a $100 \mathrm{~Hz}$ podem ser usados como referência.

Os valores apresentados na Tabela 1 são orientações para valores de PPV tanto nas fundações quanto em plano horizontal em pavimentos superiores da edificação. Segundo a DIN 4150-3 (1999), valores medidos abaixo dos limites especificados na Tabela 1 são considerados não danosos às estruturas civis.

Na DIN 4150-3 (1999) chama-se a atenção para o fato de que, mesmo que os valores limites aceitáveis sejam cumpridos, se danos que reduzem a funcionalidade do edifício ocorrerem, é de supor-se que outras causas poderão ser responsáveis. Ao contrário, também, exceder os valores limites não necessariamente induzirá danos; mas sendo eles significativamente excedidos, investigações são necessárias.

\section{CARACTERIZAÇÃO DO LOCAL INVESTIGADO}

O sistema ferroviário escolhido como caso de estudo foi o que atende a população da Região Metropolitana de João Pessoa. A malha ferroviária da região, inaugurada em 1881, possui extensão total de $30 \mathrm{~km}$, dez estações e atende aos municípios de Santa Rita, Bayeux, João Pessoa e Cabedelo. Especificamente, no trecho de ferrovia que interliga os municípios de Cabedelo e João Pessoa, observa-se um processo de fissuração em elementos estruturais e de vedação em edificações nas margens da ferrovia. Suspeita-se que o tráfego de trens possa ser causa das patologias encontradas no local.

Para a escolha desta ferrovia, consideraram-se os seguintes critérios: facilidade logística para realização dos testes, inserção urbana, a ferrovia possuir características comuns ao cenário nacional, variações de tipos de veículos em circulação e de carga transportada (trens de passageiros e de carga). Além destes crité- rios, a área de estudo deveria apresentar edificações com potenciais problemas de fissuração (que seriam eventuais possíveis danos causados pela vibração devido ao tráfego de trens).

Foram realizadas vistorias em edificações no local, contemplando um diagnóstico geral do estado de conservação e grau de fissuração das construções. Procurou-se identificar as distâncias entre as edificações e a ferrovia, o tipo de edificação afetada (se comercial ou residencial; padrão construtivo; número de pavimentos; tipos de fundação) e caracterizar as fissuras (espessuras, profundidades, extensões, localização etc.). Também foi realizada uma análise comparativa entre a incidência de fissuras nas edificações próximas e mais afastadas da ferrovia.

De modo a caracterizar a fonte da vibração, foram levantadas a quantidade de estações em operação, extensão total e parcial (entre estações) e seqüência de distribuição dessas estações ao longo da ferrovia. Foi realizado levantamento da freqüência dos trens de passageiros e de carga (fluxo de tráfego, número de viagens por dia) e do número de passageiros por viagem e peso por viagem para os trens de carga. A velocidade de operação foi monitorada. Também foi realizado levantamento topográfico em planimetria e altimetria visando identificar eventuais irregularidades nos trilhos e a existência de falhas nos elementos construtivos da ferrovia.

A fim de caracterizar o solo local, foi realizado ensaio SPT in situ. Também foi realizada uma comparação entre o tipo e estratificação dos solos próximo e mais afastado da ferrovia, observando-se serem semelhantes, com camada superficial arenosa, variando de fofa a medianamente compacta.

\section{METODOLOGIA}

Foram realizadas medições de níveis de aceleração em solo e edificações. O procedimento para realização de medições induzidas no solo e em edificações seguiram os padrões normativos vigentes (DIN 4150-3, 1999; ISO 4866, 1990). Três acelerômetros de alta sensibilidade (em torno de $1 \mathrm{~V} / \mathrm{g}$ ) foram utilizados, conectados a um equipamento de aquisição de dados, que, por vez, foi conectado a um PC Notebook.

Para a definição dos valores de velocidade, os dados 
de acelerações medidos, em Volts (V), foram convertidos para $\mathrm{mm} / \mathrm{s}^{2}$ e filtrados por um filtro digital, do tipo "passa-faixa", que permite a passagem das freqüências de certa faixa e rejeita ou atenua as freqüências fora da faixa de referência. $\mathrm{O}$ filtro utilizado foi o "Butterworth Filter", com os seguintes parâmetros: "High pass" $=10 \mathrm{~Hz}$ e "Low pass" $=150 \mathrm{~Hz}$. Foi aplicado procedimento de correção por "baseline" parabólica (YANG et al., 2003) nos sinais de aceleração medidos, a fim de evitar "drifts", gerados devido aos níveis de ruído, que podem ocorrer nos próprios instrumentos de medição ou ser devido aos níveis de vibração no ambiente, que podem afetar o processo de integração. Em seguida, os sinais filtrados $\left(\mathrm{em} \mathrm{mm} / \mathrm{s}^{2}\right)$ foram integrados e, desta forma, foram obtidas as respectivas velocidades, em $\mathrm{mm} / \mathrm{s}$. Foram, então, determinados os valores máximos de velocidade de partícula (PPV). Em seqüência, os valores de PPV foram comparados com os respectivos valores limites admitidos pela DIN 4150-3, na faixa de freqüência verificada, sendo àqueles medidos dentro da faixa de domínio adotada pela operadora da ferrovia.

\section{RESULTADOS E DISCUSSÕES}

Foram realizadas visitas de inspeção visual nas edificações localizadas às margens de um trecho desta ferrovia. Na região selecionada para realização das medições, com extensão de 500 metros ao longo da ferrovia e 150 metros de largura, foi observado, no entorno da via férrea, um grande número de edificações com um processo de fissuração em elementos estruturais e de vedação. Na região, há edificações residenciais e comerciais, sendo o primeiro tipo predominante. As edificações são em alvenaria, sendo construídas sob fundações rasas, do tipo radier, com padrões de revestimento variados (apresentam-se edificações revestidas com reboco, cerâmica etc.). Quanto às idades das construções, foram coletadas informações, junto aos moradores, que relatam idades de até 93 anos, bem como edificações construídas no ano de 2007.

Através de vistorias para caracterização das fissuras, observou-se que em edificações mais próximas à ferrovia (com distâncias de até $25 \mathrm{~m}$ ), 68 \% das construções vistoriadas apresentam algum nível de fissuração. Para as edificações mais afastadas (com distâncias da ferrovia de $25 \mathrm{~m}$ até $80 \mathrm{~m}$ ), somente $27 \%$ das vistoriadas apresentaram alguma incidência de fissuras nas fachadas. $\mathrm{O}$ fato da incidência de fissuras ser maior nas edificações mais próximas à ferrovia, reforçou a hipótese de que a vibração produzida pelo tráfego de trens de superfície poderia ser a causa do alto índice de fissuração nas edificações da região.

As medições foram efetuadas nos dois sentidos do percurso. Para os trens de passageiros, as medidas fo- ram efetuadas em horários variados, levando-se em consideração a quantidade de usuários presente em cada viagem, o que resulta em oscilações do peso da composição. A taxa de aquisição utilizada foi de 1.200 pontos/segundo, com um tempo total de medição de cada registro igual a $40 \mathrm{~s}$, totalizando 48.000 pontos por medição.

Inicialmente, os sinais foram adquiridos em diferentes distâncias da ferrovia, nas três direções. A Figura 1 apresenta a relação entre os valores de PPV, nas diferentes direções de medição, e as variações de velocidade de tráfego dos trens. Por meio desta série de medições, foi possível concluir que as maiores amplitudes de PPV ocorrem na direção vertical.

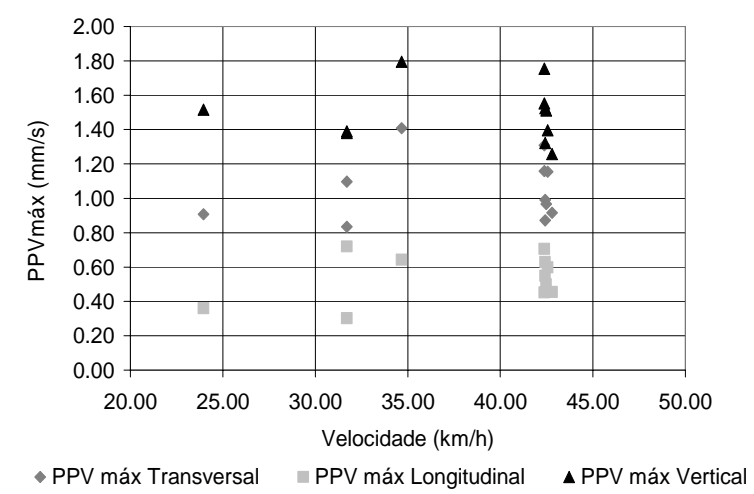

Figura 1. Gráfico de PPV máxima, nas três direções, versus velocidade de tráfego dos trens

Optou-se pela realização de medições apenas na direção vertical. Assim, foi possível a medição em mais de um ponto, simultaneamente, com os três acelerômetros dispostos em diferentes distâncias da ferrovia. Com isto, obteve-se um maior número de amostras para um mesmo tipo de composição (igual peso e comprimento) e nas mesmas condições de tráfego (velocidade, condições de aceleração ou desaceleração), o que permitiu uma melhor avaliação da propagação das ondas com a distância. As medições realizadas ficaram restritas às calçadas das edificações, devido à dificuldade de acesso ao interior das mesmas. Foram realizadas 68 medições e, em seqüência, foram obtidos os respectivos gráficos da aceleração e gráficos velocidade, no domínio do tempo.

As Figuras 2(a) e 2(b) apresentam croquis de localização de alguns pontos de medição, com valores médios de PPV obtidos, simultaneamente, com três acelerômetros, nas distâncias (d) descritas. As representações (1), (2) e (3), identificam as medidas de PPV simultâneas, assim como as demais seqüências representadas: (a), (b) e (c); (A), (B) e (C); (I), (II) e (III); (D), (E) e (F). Cabe observar que os valores da Figura 2(a) foram medidos em trecho de ferrovia com dormentes monoblocos e os da Figura 2(b) medidos em trecho com dormentes biblocos. 

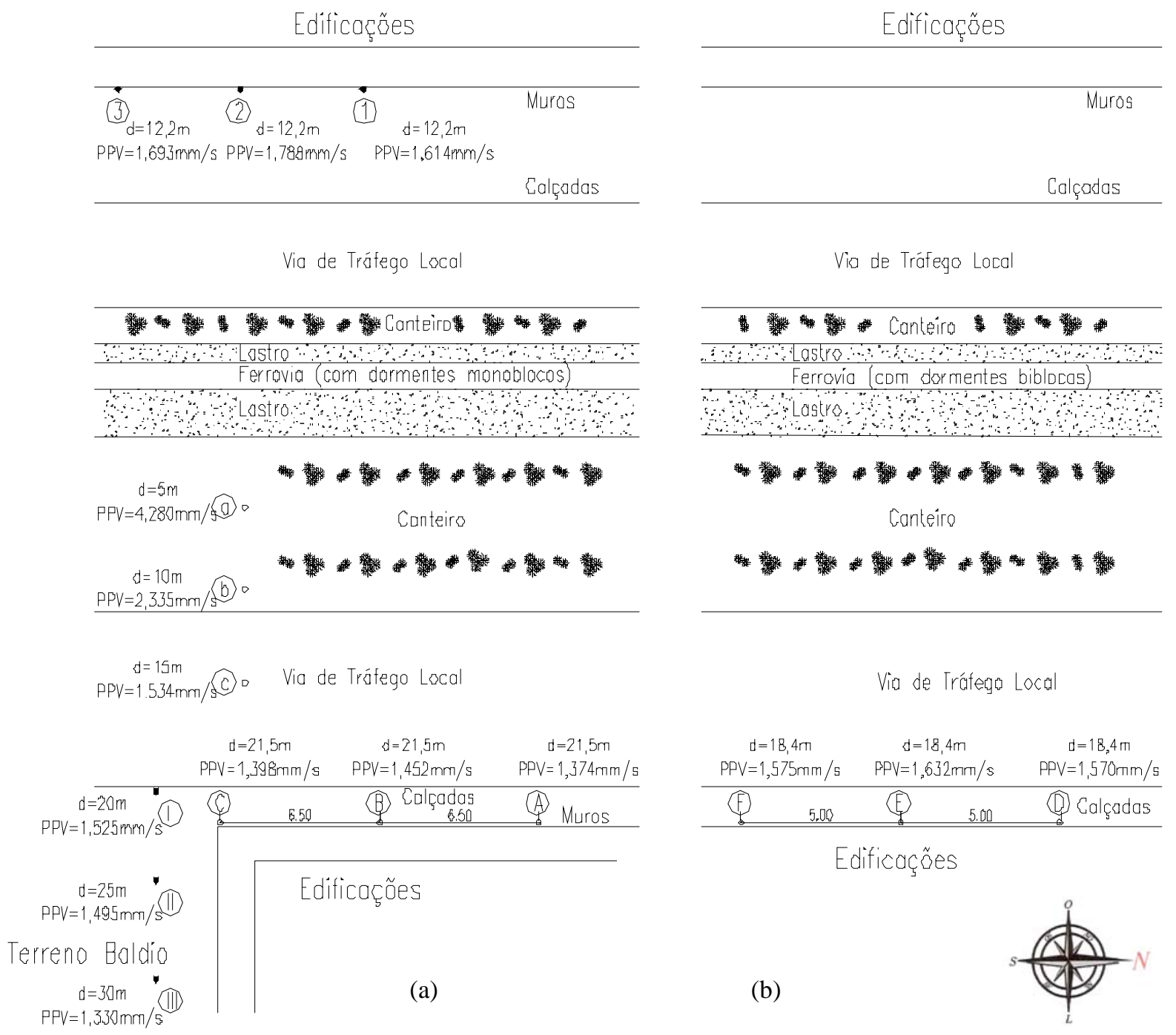

Figura 2. Croqui de algumas medições simultâneas realizadas: (a) em trecho de ferrovia com dormentes monoblocos; (b) em trecho de ferrovia com dormentes biblocos

Para proceder com as análises das medidas de PPV e poder comparar os níveis de vibração do local com os valores limites admitidos por norma (DIN 4150-3, 1999), os sinais, no domínio do tempo, foram convertidos para o domínio da freqüência (aplicando-se a Transformada Rápida de Fourier - FFT), a fim de verificar a faixa de freqüência predominante da vibração.

Verificando os espectros dos sinais medidos a 15 metros da ferrovia, observaram-se componentes mais significativas de freqüência em torno de $30 \mathrm{~Hz}$ a $80 \mathrm{~Hz}$, para as distâncias observadas.

Tomando os valores de PPV medidos e a faixa de freqüência de excitação, e comparando-os com os da norma, pôde-se concluir que os valores de velocidade estão em acordo com a norma DIN 4150-3 (1999), haja vista que o limite a partir do qual poderiam ocorrer possíveis danos, segundo a referida norma, para aquela faixa de freqüência, seria de $15 \mathrm{~mm} / \mathrm{s}$. Todavia, a hipótese de que o nível de incidência de fissuras na região mais próxima à ferrovia ser devido à vibração produzida pelo tráfego de trens não foi descartada, pois, como descrito anteriormente, no trecho em estudo, também há circulação de trens de carga.

Por questões de segurança de tráfego, já que a via é singela, os trens de transporte de carga circulam à noite, usualmente em horários incertos durante a madrugada. Tal fato não permitiu a realização de medições de níveis de vibração para este tipo de transporte, devido a problemas logísticos em manter os equipamentos em funcionamento (em estado de espera) e problemas relacionados a questões de segurança. Para suprir a falta da realização destas medições buscou-se, através de modelos estatísticos, simular os níveis de vibração que seriam produzidos pelo tráfego dos trens de carga na região, em diferentes distâncias da ferrovia, a partir de condições de operação atualmente praticadas pela operadora de transporte de cargas da região.

O objetivo destas simulações foi estimar os valores de PPV para diferentes configurações de trens de carga (diferentes pesos e velocidades de tráfego). 
A realização das simulações fundamentou-se em dados de medições de níveis de vibração em diferentes distâncias, para diferentes composições ferroviárias e diferentes velocidades de tráfego, adquiridos durante as medições dos trens de passageiros. Uma base amostral com 52 elementos foi utilizada, com as seguintes variações de valores das variáveis de influência:

- Distância à ferrovia: de 2 a 30 metros;

- Massa do veículo: de 145 a 170 tons; e

- Velocidade de tráfego: de 24 a 43 km/h.

Foi utilizado o "software" SISREN - Sistema de Regressão Linear e Redes Neurais Artificiais, no tratamento dos dados, através de processo de regressão numérica usando inferência estatística.

A Equação 1, obtida por regressão numérica, foi o modelo estatístico-matemático que permitiu a simulação dos valores de PPV:

$$
P P V=-5,866+\frac{1,443}{d}+4,416 \cdot 10^{-5} \cdot m-0,004 \cdot v
$$

em que,

$$
\begin{aligned}
P P V: & \text { velocidade de pico da partícula }[\mathrm{mm} / \mathrm{s}] ; \\
d: & \text { distância da ferrovia }[\mathrm{m}] ; \\
m: & \text { massa do veículo }[\mathrm{kg}] ; \\
v: & \text { velocidade do tráfego }[\mathrm{km} / \mathrm{h}] .
\end{aligned}
$$

Com o modelo definido, realizaram-se projeções para determinação dos valores de PPV, utilizando as variáveis do próprio modelo, quais sejam: distância (à ferrovia), peso do veículo e velocidade de tráfego.

A estimativa dos valores de PPV para os trens de carga foi obtida inserindo os seguintes valores na Equação 1: distância (à ferrovia) igual a $15 \mathrm{~m}$, massa da composição (massa do veículo mais carga transportada) variando entre 200 ton e 900 ton (os dados de fluxo de carga na ferrovia, obtidos com a operadora da ferrovia em estudo, apontam para um valor médio de carga transportada por viagem igual a 850 ton) e velocidade de tráfego com valores entre $20 \mathrm{~km} / \mathrm{h}$ e $30 \mathrm{~km} / \mathrm{h}$ (segundo dados da operadora, atualmente, os trens de carga circulam com uma velocidade média de $25 \mathrm{~km} / \mathrm{h}$ ).

Nas simulações realizadas para os trens de carga, verificou-se que os valores de PPV para os trens de carga superam os valores limites encontrados em norma (DIN 4150-3, 1999). Considerando valores de massa da composição iguais ou acima de 500 t, na faixa de freqüência de $30 \mathrm{~Hz}$ a $60 \mathrm{~Hz}$, para qualquer das velocidades entre $20 \mathrm{~km} / \mathrm{h}$ e $30 \mathrm{~km} / \mathrm{h}$, os valores de PPV obtidos estariam acima de $16 \mathrm{~mm} / \mathrm{s}$, superando o limite de $15 \mathrm{~mm} / \mathrm{s}$ definido em norma, aplicável ao local. Verificou-se, ainda, que para valores de massa do veículo de até 473 ton e velocidade de $20 \mathrm{~km} / \mathrm{h}$ (praticada pela operadora de trens de carga) a distância à ferrovia necessária para reduzir os níveis de vibração aos especificados por norma, deveria ser em torno de 30 m e não de 15 m, para cada lado da ferrovia.

\section{CONCLUSÕES}

A partir de vistorias realizadas nas edificações localizadas às margens de trecho da ferrovia que atende a Região Metropolitana de João Pessoa, foi possível observar que as mesmas apresentam variados tipos de fissuras e níveis de incidência. Nas edificações mais afastadas da ferrovia (a cerca de $80 \mathrm{~m}$ ), as condições de intempérie (umidade e temperatura), tipo de solo e padrão construtivo eram os mesmos encontrados nas edificações mais próximas à ferrovia (a $30 \mathrm{~m}$ ). Entretanto, a incidência de fissuração nas edificações mais próximas era expressivamente maior que nas mais afastadas. Tal fato sugeriu a hipótese de que os níveis de vibração produzidos pelo tráfego de trens de superfície aos quais essas edificações estão submetidas possam ser causa do alto índice de fissuração. A fim de verificar esta hipótese, foi realizado monitoramento, através de medições experimentais de níveis de vibração, em solo e em edificações.

Os níveis de vibração induzidos pelo tráfego de trens de passageiros, medidos ao longo do citado trecho da ferrovia, apresentaram-se abaixo dos limites relacionados a danos em edificações definidos em normas. Ou seja, a distância entre a fonte da vibração (ferrovia) e o receptor (edificações), é suficiente para o favorecimento do amortecimento geométrico da vibração produzida pelo tráfego de trens de passageiros.

Todavia, simulações realizadas, a partir de condições de operação atualmente praticadas pela operadora de transporte de cargas, indicaram a possibilidade desta faixa de domínio não atender as necessidades de redução dos níveis de vibração produzidos pelo tráfego de trens de carga na região. Isto é, os níveis de vibração esperados a $15 \mathrm{~m}$ de cada lado da ferrovia, para os trens de carga, seriam superiores aos aceitáveis para a tipologia estrutural das edificações da região em estudo. Tal fato leva a evidência de que o nível de fissuração encontrado na região seja devido ao tráfego dos trens de transporte de cargas.

\section{AGRADECIMENTOS}

Ao $\mathrm{CNPq}$ e CAPES pelo apoio financeiro, através de auxílio à pesquisa (Edital Universal) e bolsa de estudos para a mestranda, respectivamente.

\section{REFERÊNCIAS BIBLIOGRÁFICAS}

ASSOCIAÇÃO BRASILEIRA DE NORMAS TÉCNICAS (1986). NBR 9653. Guia para avaliação dos efeitos provocados pelo uso de explosivos nas minerações em áreas urbanas. Norma de Procedimento. São Paulo.

Auersch, L. (2006) Ground vibration due to railway traffic - The calculation of the effects of moving static loads and their experimental verification. Journal of Sound and Vibration 293, pp. 599-610. 
Athanasopoulos, G.A.; Pelekis, P.C.; Anagnostopoulos, G.A. (2000), Effect of soil stiffness in the attenuation of Rayleigh-wave motions from field measurements, Soil Dynamics and Earthquake Engineering, vol. 19, pp.277- 288.

Bacci, D.C.; Landim, P. M. B.; Eston, S.M. \& Iramina, W. S. (2003) Principais normas e recomendações existentes para o controle de vibrações provocadas pelo uso de explosivos em áreas urbanas Parte I. Revista Escola de Minas, Ouro Preto, 56(1), pp. 51-57.

Bahrekazemi, M. (2004) Train-Induced Ground Vibration and Its Prediction. Department of Civil and Architectural Engineering, Royal Institute of Technology, Stockholm.

BRITISH STANDARD. BS 7385. (1990) Evaluation and Measurement for Vibration in Buildings - Part 1. Guide for measurement of vibrations and evaluation of their effects on buildings.

DEUTSCHES INSTITUT FÜR NORMUNG E.V. (1999) DIN 4150-3. Structural Vibration - Effects of Vibration on Structures.

INTERNATIONAL ORGANIZATION FOR STANDARDIZATION (1990). ISO 4866. Mechanical vibration and shock - Vibration of buildings - Guidelines for the measurement of vibrations and evaluation of their effects on buildings.

Yang, J.; LI, J.B. \& LIN, G. (2006) A simple approach to integration of acceleration data for dynamic soil-structure interaction analysis. Soil Dynamics and Earthquake Engineering 26, pp. 725-734.

Kim, D. \& LEE, J. (2000) Propagation and Attenuation Characteristics of Various Ground Vibrations. Soil Dynamics and Earthquake Engineering 19, pp. 115-126.

Semprebone, P. da S. (2006) Desgastes em trilhos ferroviários - Um estudo teórico. 153 p. Dissertação (Mestrado) - Curso de Pósgraduação da Faculdade de Engenharia, Universidade Estadual de Campinas, Campinas. 